\title{
Return to play and risk of repeat concussion in collegiate football players: comparative analysis from the NCAA Concussion Study (1999-2001) and CARE Consortium (2014-2017)
}

\author{
Michael McCrea (D) ,' Steven Broglio, ${ }^{2}$ Thomas McAllister, ${ }^{3}$ Wenxian Zhou, ${ }^{4}$ Shi Zhao, ${ }^{4}$ \\ Barry Katz, ${ }^{4}$ Maria Kudela, ${ }^{5}$ Jaroslaw Harezlak, ${ }^{6}$ Lindsay Nelson, ${ }^{7}$ Timothy Meier, ${ }_{1}^{8,9}$ \\ Stephen William Marshall, ${ }^{10}$ Kevin M Guskiewicz, ${ }^{11}$ On behalf of CARE Consortium \\ Investigators
}

For numbered affiliations see end of article.

\section{Correspondence to} Dr Michael McCrea,

Neurosurgery, Medical College of Wisconsin, Milwaukee, WI 53226, USA;

mmccrea@mcw.edu

Received 14 January 2019 Revised 9 April 2019 Accepted 11 April 2019 Published Online First 29 April 2019

\section{Check for updates}

(C) Author(s) (or their employer(s)) 2020. No commercial re-use. See rights and permissions. Published by BMJ.

To cite: McCrea M, Broglio S, McAllister T, et al. Br J Sports Med 2020;54:102-109.

\section{ABSTRACT}

Objective We compared data from the National Collegiate Athletic Association (NCAA) Concussion Study (1999-2001) and the NCAA-Department of Defense Concussion Assessment, Research and Education (CARE) Consortium (2014-2017) to examine how clinical management, return to play (RTP) and risk of repeat concussion in collegiate football players have changed over the past 15 years.

Methods We analysed data on reported duration of symptoms, symptom-free waiting period (SFWP), RTP and occurrence of within-season repeat concussion in collegiate football players with diagnosed concussion from the NCAA Study $(n=184)$ and CARE $(n=701)$.

Results CARE athletes had significantly longer symptom duration (CARE median $=5.92$ days, IQR=3.02-9.98 days; NCAA median $=2.00$ days, IQR $=1.00-4.00$ days), SFWP (CARE median $=6.00$ days, IQR $=3.49-9.00$ days; NCAA median $=0.98$ days, IQR=0.00-4.00 days) and RTP (CARE median $=12.23$ days, IQR=8.04-18.92 days; NCAA median $=3.00$ days, $I Q R=1.00-8.00$ days) than NCAA Study athletes (all $p<0.0001$ ). In CARE, there was only one case of repeat concussion within 10 days of initial injury (3.7\% of within-season repeat concussions), whereas $92 \%$ of repeat concussions occurred within 10 days in the NCAA Study $(p<0.001)$. The average interval between first and repeat concussion in CARE was 56.41 days, compared with 5.59 days in the NCAA Study (M difference $=50.82$ days; $95 \% \mathrm{Cl} 38.37$ to 63.27; $p<0.0001)$.

Conclusion Our findings indicate that concussion in collegiate football is managed more conservatively than 15 years ago. These changes in clinical management appear to have reduced the risk of repetitive concussion during the critical period of cerebral vulnerability after sport-related concussion (SRC). These data support international guidelines recommending additional time for brain recovery before athletes RTP after SRC.

\section{INTRODUCTION}

Prior to the 1990s, sport-related concussion (SRC) garnered little attention from the sports medicine and scientific communities. Systematic protocols for injury management and return to play (RTP) after concussion were seldom used. ${ }^{1}{ }^{2}$ Athletes commonly returned to participation within a day

\section{Key points}

What are the findings?

- In our analysis, college football players with concussion in the National Collegiate Athletic Association (NCAA)-Department of Defense Concussion Assessment, Research and Education (CARE) Consortium (2014-2017) were withheld from play for an average of 16 days after injury.

- On average, return to play by current-day CARE athletes was nearly 10 days longer than concussed football players in the earlier NCAA Concussion Study (1999-2001).

- The rate of same-season repeat concussion in CARE was $41 \%$ lower than the NCAA Study, and CARE athletes were at significantly lower risk of repeat concussion within the first 10 days after initial injury.

- Improvements in clinical management over the past 15 years allow athletes additional time for brain recovery after sport-related concussion (SRC) and appear to have reduced the risk of repetitive concussion during the critical period of cerebral vulnerability after SRC.

How might it impact on clinical practice in the future?

- Findings from this study support contemporary international consensus recommendations for the management of SRC.

- Clinicians should be aware of these consensus recommendations and supporting evidence from this study and others that inform best practice in injury management and return to play after SRC.

after concussion, often during the same game or practice. $^{3}{ }^{4}$ Athletes had limited awareness of the signs, symptoms and the potential seriousness of returning to play while symptomatic. ${ }^{5}$

The National Collegiate Athletic Association (NCAA) Concussion Study (1999-2001) was the first large, prospective study of the natural time course of recovery in collegiate football players. ${ }^{67}$ Key findings from this work indicated that the initial 
$7-10$ days after SRC was the typical time course of recovery, and the period during which athletes were at greatest risk of repeat concussion within the same football season. ${ }^{6}$

Those findings provided early support for the theory that a window of cerebral vulnerability exists after concussion, during which the brain is not yet physiologically recovered and remains at heightened risk for secondary injury if exposed to additional trauma in the acute phase. This theory was initially based on animal studies demonstrating the course of neurophysiological changes after concussion, commonly referred to as the 'neurometabolic cascade.${ }^{89}$ Preliminary studies have reported a similar phenomenon in athletes after SRC. ${ }^{10}$

Over the past 20 years, SRC has transformed from relative obscurity to worldwide recognition as a significant public health problem. ${ }^{11-14}$ Sporting and medical organisations have leveraged research towards development of standardised protocols for injury management and RTP after concussion. ${ }^{14-17}$ Public health campaigns have been geared towards educating healthcare professionals, athletes and key stakeholders on best practices in concussion care. ${ }^{18}$ Specific to the setting of college athletics, there have been major efforts over the past 10 years to promote best clinical practices in concussion management, and to instigate broader cultural changes around awareness of SRC at both the institutional and athlete level. ${ }^{19}{ }^{20}$ In the past, there was no universal mandate for concussion management at the national level. In contrast, current policies now require that NCAA institutions demonstrate compliance with the NCAA Concussion Safety Protocol with respect to preseason athlete education, preparticipation assessment, concussion diagnosis, postinjury management and RTP after SRC. ${ }^{19}$

The NCAA-Department of Defense (DoD) Concussion Assessment, Research and Education (CARE) Consortium marks the largest and most comprehensive study to date of SRC in collegiate athletes and US military service academy cadets. ${ }^{21}$ CARE collects detailed data on baseline characteristics of athletes and cadets across all NCAA sports, and closely monitors recovery and RTP after concussion during NCAA sport participation and military service academy training.

Through a unique opportunity to compare large, prospective data sets from the NCAA Concussion Study (1999-2001) and the CARE Consortium (2014-2017), the current study examined the extent to which common practice in injury management and RTP after concussion in collegiate football players has changed over the past 15 years. A secondary objective was to investigate how changes in clinical practice may have impacted risk of same-season repeat concussion. We hypothesised that current-day college athletes would observe a longer period of recovery before RTP after SRC and have a lower rate of repeat concussions during the early window of recovery after concussion, compared with athletes in the NCAA Concussion Study. ${ }^{12}$

\section{METHODS}

\section{Overview of studies}

The NCAA Concussion Study was a prospective cohort study that enrolled 2905 NCAA football players from 25 NCAA Division I, II and III universities from 1999 to 2001. The detailed methods and findings of the NCAA Study have been previously reported. ${ }^{6}$ Concussed athletes $(n=184)$ underwent detailed clinical assessments immediately, 3 hours, and 1, 2, 3, 5, 7 and 90 days after injury. Concussion was defined according to the American Academy of Neurology (AAN) Guideline for Management of Sports Concussion. ${ }^{22}{ }^{23}$ Detailed data on acute injury, clinical management, RTP and repeat concussion were collected.
The NCAA-DoD CARE Consortium is a prospective cohort study that has enrolled over 40000 athletes at 30. NCAA Division I, II and III institutions since 2014. ${ }^{21}$ The CARE Clinical Study Core involves preseason baseline testing of all athletes and cadets on a detailed concussion assessment battery. Concussion is defined according to the consensus definition from the US DoD evidence-based guidelines, which closely parallels the AAN definition. ${ }^{24}$ The CARE postinjury protocol involves follow-up testing of concussed athletes at several time points $(<6$ hours, 24-48 hours, time of asymptomatic and start of RTP protocol, unrestricted RTP, 6 months after injury). Consistent with the NCAA Study, detailed information on clinical recovery, management, RTP and repeat concussion is recorded.

Consistencies across the two studies were leveraged to maximise the validity of our comparative analysis. The geographic and competitive distribution of sites across Divisions I-III in CARE and the NCAA Study was equivalent, with both studies providing a national representation of college football players (FreemanHalton Fisher's exact test for NCAA Division, $p=0.76$ ). In both studies, trained physicians and athletic trainers made the diagnosis of concussion, assessment of recovery and decisions on RTP. Further, both the AAN and DoD definitions base the diagnosis of concussion on observed mechanism of injury and similar clinical criteria. The methodology used to measure our primary outcomes of recovery and RTP time were also parallel across the two studies; both studies employed similar standardised checklists to assess symptoms. The NCAA Study used the Graded Symptom Checklist ${ }^{67}$ and CARE used a more recent iteration, the Sport Concussion Assessment Tool-Third Edition. ${ }^{12}$ RTP was not dictated by the research protocol in either study. Recommended clinical practice guidelines for concussion management evolved significantly during the interval between the NCAA Study and CARE, which was a major basis for comparing RTP in the two studies separated by approximately 15 years. ${ }^{14} 1920$

\section{NCAA and CARE cohorts}

To parallel the NCAA Study, the current analysis included only data on concussed NCAA football players from CARE. In total, our analysis included data on 184 concussions from the NCAA Concussion Study (1999-2001) and 701 concussions from CARE (2014-2017 football seasons). Sample characteristics for the NCAA and CARE cohorts are presented in table 1.

\section{Statistical analysis}

Acute injury characteristics were compared between studies to determine the extent to which injury severity may influence our primary analysis. Our main analysis compared key variables measuring duration of symptoms (time from injury to asymptomatic point), symptom-free waiting period (SFWP) and total time for RTP after SRC between the two studies. In both studies, SFWP was calculated based on the time (days) from the point at which the athlete was determined to be asymptomatic and began the RTP protocol to the point at which the athlete resumed participation in unrestricted football activities; total RTP time was calculated on the number of days from injury to return to unrestricted football-related activities.

In both studies, the data collection protocol was extensive and time sensitive, which resulted in a modest amount of missing data. For our analysis, data completeness on our key variables was $86 \%$ for the NCAA Study and $88 \%$ for CARE. To examine the potential effect of missing data on our main analyses, we compared acute injury characteristics (loss of consciousness (LOC), post-traumatic amnesia (PTA), symptom 
Original article

Table 1 Sample and acute injury characteristics for NCAA Concussion Study and CARE Consortium cohorts

\begin{tabular}{|c|c|c|c|c|}
\hline Characteristics & $\begin{array}{l}\text { NCAA Concussion Study (1999-2001) } \\
\text { Mean (SD) }\end{array}$ & $\begin{array}{l}\text { CARE Consortium (2014-2017) } \\
\text { Mean (SD) }\end{array}$ & $\begin{array}{l}\text { Mean difference } \\
(95 \% \mathrm{Cl})\end{array}$ & $P$ value \\
\hline Concussions (n) $\dagger$ & 184 & 701 & & \\
\hline Age (years)* & $19.70(1.46)$ & $19.03(1.3)$ & $-0.67(-0.9$ to -0.43$)$ & $<0.0001$ \\
\hline Academic year* & $2.55(1.18)$ & $1.81(1.03)$ & $-0.74(-0.92$ to -0.55$)$ & $<0.0001$ \\
\hline Height (inches) & $73.17(2.69)$ & $73.5(2.94)$ & $0.33(-0.13$ to 0.78$)$ & 0.16 \\
\hline Body weight (lb) & $227.91(45.25)$ & $229.38(45.17)$ & $1.47(-6$ to 8.93$)$ & 0.70 \\
\hline Participation in football (years) & $8.94(2.94)$ & $9.38(3.28)$ & $0.44(-0.06$ to 0.94$)$ & 0.09 \\
\hline Prior concussions $(n)^{*}$ & $0.55(0.92)$ & $0.69(0.97)$ & $0.14(-0.01$ to 0.3$)$ & 0.06 \\
\hline ADHD & $4.3 \%$ & $7.4 \%$ & & 0.19 \\
\hline Learning disorder & $1.6 \%$ & $4.4 \%$ & & 0.09 \\
\hline \multicolumn{5}{|l|}{ NCAA sites } \\
\hline Division I & 19 & 20 & & 0.76 \\
\hline Division II & 3 & 5 & & \\
\hline Division III & 3 & 5 & & \\
\hline \multicolumn{5}{|l|}{ Acute injury characteristics } \\
\hline LOC, n (\%) & $12(6.3 \%)$ & $35(5.1 \%)$ & $-33.84(-75.77$ to 8.09$)$ & 0.41 \\
\hline Median duration (s) & 30.0 & 5.0 & & 0.13 \\
\hline Mean duration (s) & $52.9(67.42)$ & $19.06(51.78)$ & & \\
\hline PTA, n (\%) & $44(24.0 \%)$ & $104(15.1 \%)$ & -66.66 (-154.3 to 20.98) & 0.004 \\
\hline Median duration (min) & 30.0 & 10.0 & & 0.14 \\
\hline Mean duration (min) & $104.4(282.4)$ & $37.74(118.45)$ & & \\
\hline LOC or PTA (\%) & 28.3 & 17.9 & & 0.003 \\
\hline
\end{tabular}

${ }^{*}$ Effect sizes: age $(d=-0.47)$, academic year $(d=-0.64)$, number of prior concussions $(d=0.15)$.

tConcussion definition: (1) NCAA Concussion Study: Concussion was defined according to the American Academy of Neurology Guideline for Management of Sports Concussion, as an injury resulting from a blow to the head causing an alteration in mental status and one or more symptoms of headache, nausea, vomiting, dizziness/balance problems, fatigue, difficulty sleeping, drowsiness, sensitivity to light or noise, blurred vision, memory difficulty and difficulty concentrating. ${ }^{22}$ 23 (2) CARE Consortium: Concussion was defined according to the consensus definition from the US Department of Defense (DoD) evidence-based guidelines, which define concussion as 'a change in brain function following a force to the head, which may be accompanied by temporary loss of consciousness, but is identified in awake individuals with measures of neurologic and cognitive dysfunction. $^{24}$

ADHD, attention-deficit hyperactivity disorder;CARE, Concussion Assessment, Research and Education; LOC, loss of consciousness;NCAA, National Collegiate Athletic Association; PTA, post-traumatic amnesia.

severity 24 hours after injury) and concussion history in athletes with missing and non-missing data related to time to recovery, SFWP and RTP. None of the covariates were associated with missing data on duration of symptoms, SFWP and RTP time. Similar to the NCAA Study, multiple imputation was conducted for imputing symptom duration, SFWP and RTP. ${ }^{67}$ LOC, duration of LOC, PTA, duration of PTA, symptom severity 24 hours after injury and total number of previous concussions were used for the Markov chain Monte Carlo method of multiple imputation. Five imputed data sets were obtained first and then pooled estimates were calculated for comparing differences of days for symptom duration, SFWP and RTP for CARE. ${ }^{25}$

Independent samples t-tests were used to compare means of sample characteristics and injury characteristics between the NCAA Study and CARE. Clinically relevant time intervals that matched those reported in the NCAA Study were generated for duration of symptoms, SFWP and RTP. Pooled estimates of means and SDs were calculated from imputed symptom duration, SFWP and RTP time in CARE, then compared with NCAA Study using independent samples t-tests, with Cohen's $\mathrm{d}$ calculated to estimate the magnitude of the effect. Due to the skewed nature of the data on these main outcome variables, median and IQR statistics are also reported and Wilcoxon rank-sum tests were used to compare the distributions for symptom duration, SFWP and RTP in the NCAA Study and CARE. $\chi^{2}$ analyses (Fisher's exact tests when sample sizes were less than 5 per category) were conducted to compare categorical frequency distributions between the groups. We analysed the rate of within-season repeat concussion (per cent of concussed athletes who sustained a second concussion in the same season), interval between first and repeat concussion and frequency of repeat concussion in the first 7-10 days across the two studies. All calculations and data analyses were completed with R software, V.3.3.2.

\section{RESULTS}

Acute injury severity

Acute injury characteristics of diagnosed concussions were similar in the NCAA Study and CARE, with some indication of slightly more severe injury in the NCAA Study (table 1). Overall, $17.9 \%$ of CARE athletes had either LOC or PTA associated with their injury, compared with $28.3 \%$ in the NCAA Study $\left(\chi^{2}\right.$ test, $\mathrm{p}=0.003$ ). NCAA Study players had a higher frequency (NCAA $24.0 \%$, CARE $15.1 \%, \chi^{2}$ test, $\mathrm{p}=0.004$ ) and longer duration of PTA ( $M=104.4$ min; $S D=282.4$; median=30) than CARE athletes $(M=37.74 \mathrm{~min} ; \mathrm{SD}=118.45$; median $=10)$ ( $\mathrm{M}$ difference $=-66.66 ; 95 \% \mathrm{CI}-154.3$ to $20.98 ; \mathrm{p}=0.14)$. The occurrence (NCAA $6.3 \%$, CARE $5.1 \% ; \chi^{2}$ test, $\mathrm{p}=0.41$ ) and duration of LOC (NCAA M=52.9 s; SD=67.4; median=30; CARE $\mathrm{M}=19.06 \mathrm{~s} ; \mathrm{SD}=51.78$; median $=5) \quad(\mathrm{M}$ difference $=-33.84$; $95 \%$ CI -75.77 to $8.09 ; \mathrm{p}=0.13)$ did not differ between studies. The two study cohorts did not differ significantly on the frequency of concussion modifiers common to both studies that could potentially confound our main results, including history 


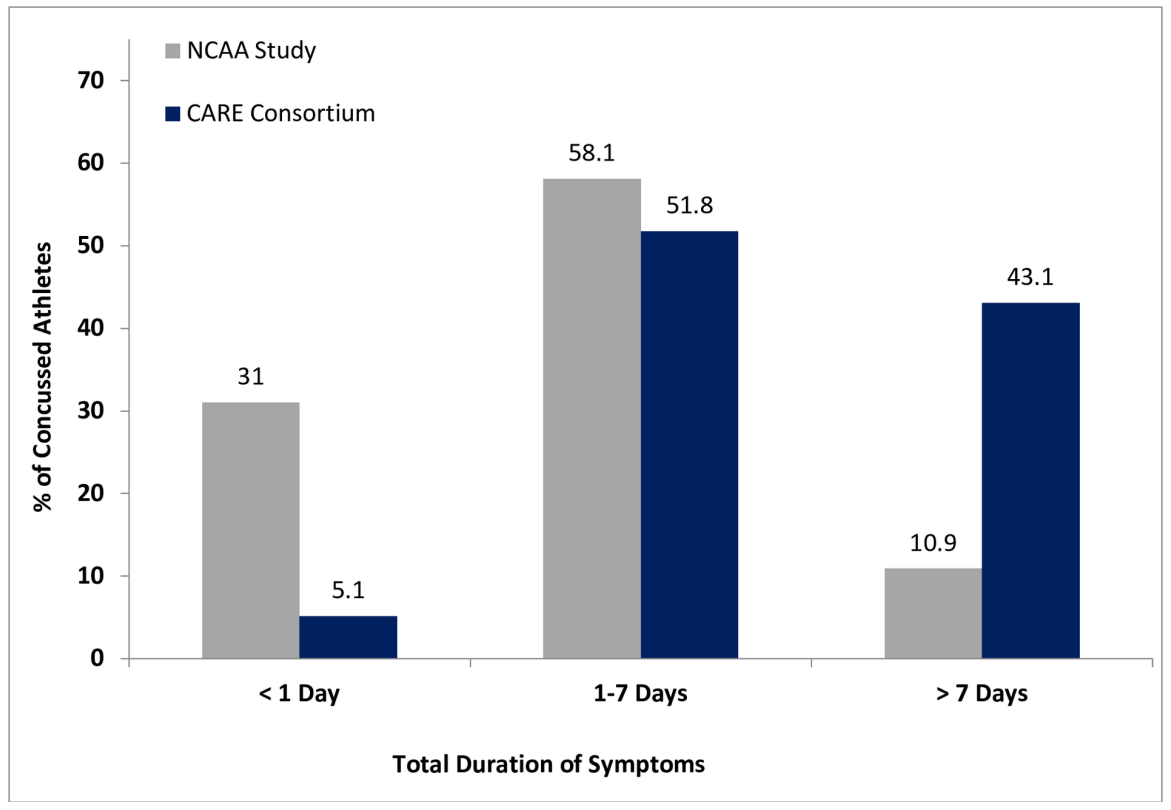

Figure 1 Distribution of total symptom duration after concussion in National Collegiate Athletic Association (NCAA) Concussion Study and Concussion Assessment, Research and Education (CARE) Consortium cohorts. $\chi^{2}$ test, $p<0.0001$.

of prior concussion, attention-deficit hyperactivity disorder or learning disorder (table 1).

\section{Reported symptom recovery}

Overall, time from injury to the asymptomatic time point in CARE athletes was 8.83 days $(\mathrm{SD}=18.75)$, compared with 3.42 days $(\mathrm{SD}=4.20)$ in NCAA Study athletes $(\mathrm{M}$ difference $=5.41$ days; 95\% CI 3.9 to $6.92 ; \mathrm{p}<0.0001)$. Median-reported symptom duration in CARE was 5.92 days ( $\mathrm{IQR}=3.02-9.98$ days), compared with 2.00 days ( $\mathrm{IQR}=1.00-4.00$ days) in the NCAA Study (Wilcoxon $\mathrm{p}<0.0001$ ). Figure 1 illustrates the difference in distribution of symptom recovery after concussion by athletes in CARE and the NCAA Study.

\section{Symptom-free waiting period}

Comparison of data from CARE to the NCAA Study indicates significant differences in the implementation of an SFWP observed by athletes before returning to play (figure 2). CARE athletes observed a mean SFWP of 7.25 days $(\mathrm{SD}=16.11)$, compared with 3.25 days $(\mathrm{SD}=9.98)$ in the NCAA Study $(\mathrm{M}$ difference $=4$ days; 95\% CI 2.14 to $5.86 ; \mathrm{p}<0.0001)$. Median SFWP in CARE was 6.00 days $(\mathrm{IQR}=3.49-9.00$ days $)$, compared

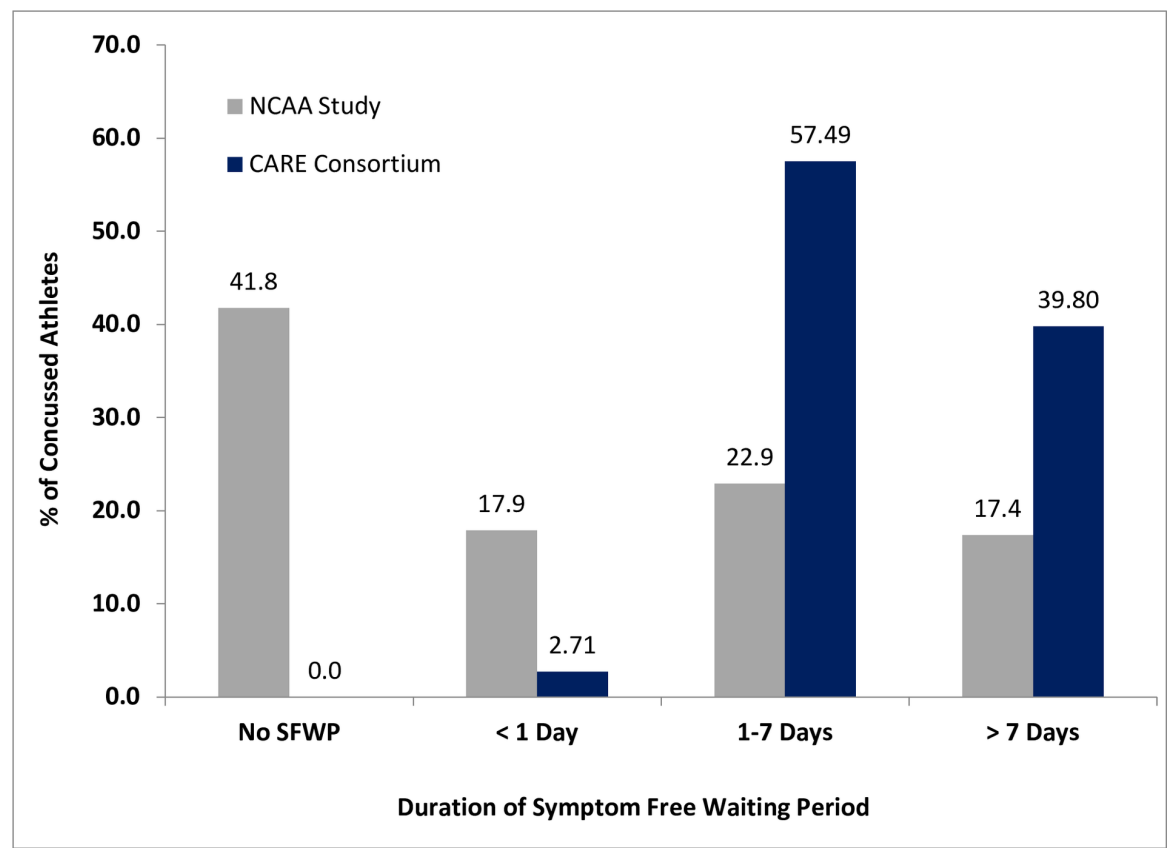

Figure 2 Distribution of symptom-free waiting period (SFWP) in National Collegiate Athletic Association (NCAA) Concussion Study and Concussion Assessment, Research and Education (CARE) Consortium cohorts. Fisher's exact test, $\mathrm{p}<0.0001$. 


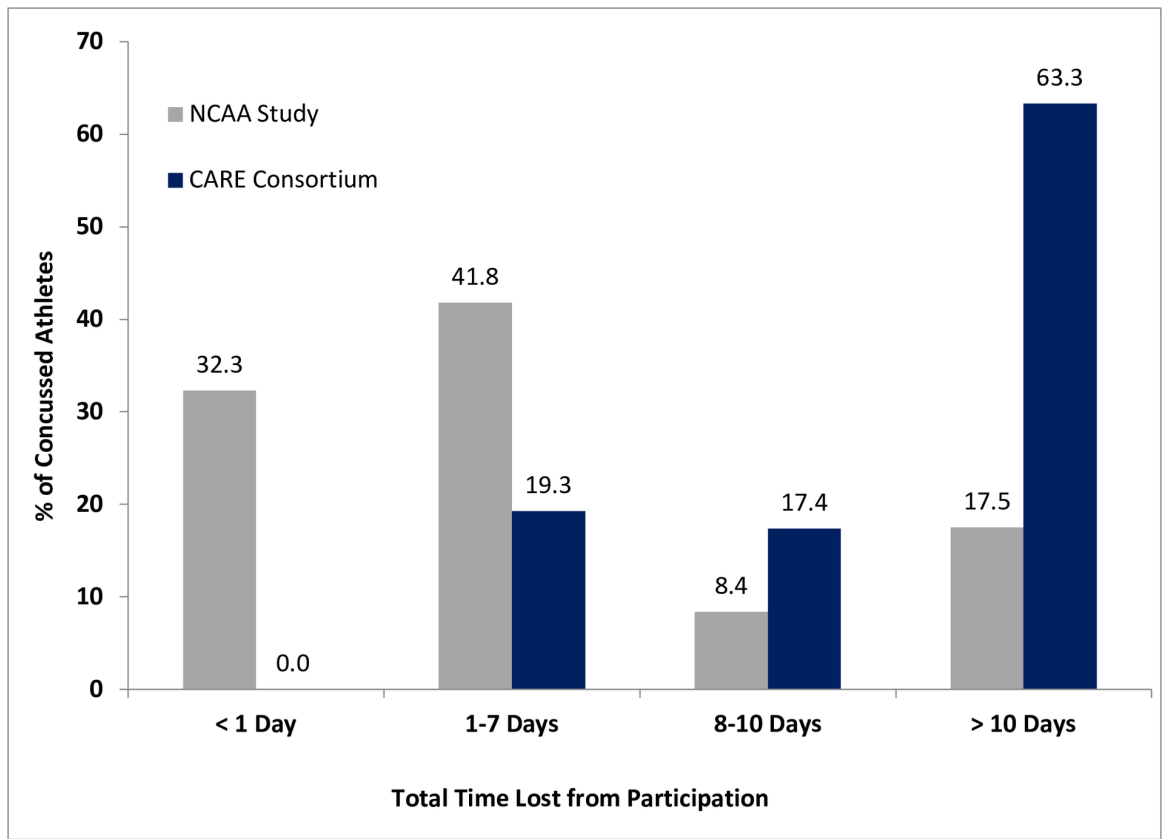

Figure 3 Distribution of time for return to play (RTP) after concussion in National Collegiate Athletic Association (NCAA) Concussion Study and Concussion Assessment, Research and Education (CARE) Consortium cohorts. Fisher's exact test, $\mathrm{p}<0.0001$.

with 0.98 days (IQR $=0.00-4.00$ days) in the NCAA Study (Wilcoxon $\mathrm{p}<0.0001$ ).

\section{Return to play}

Total time for RTP after concussion was nearly 10 days longer in CARE athletes $(M=16.08$ days; $S D=14.39)$ than the NCAA Study cohort $(M=6.67$ days; $S D=11.4)(M$ difference $=9.41$ days; 95\% CI 7.45 to 11.37 ; $<<0.0001)$. Median RTP in
CARE was 12.23 days (IQR $=8.04-18.92$ days), compared with 3.00 days ( $\mathrm{IQR}=1.00-8.00$ days) in the NCAA Study cohort (Wilcoxon $\mathrm{p}<0.0001$ ). The distribution of RTP time by CARE athletes was strikingly different from the NCAA Study (figure 3). Figure 4 presents the summed median duration of symptoms, SFWP and RTP time in the NCAA and CARE cohorts (all $\mathrm{p}<0.0001$ ), which were not significantly associated with number or prior concussions.

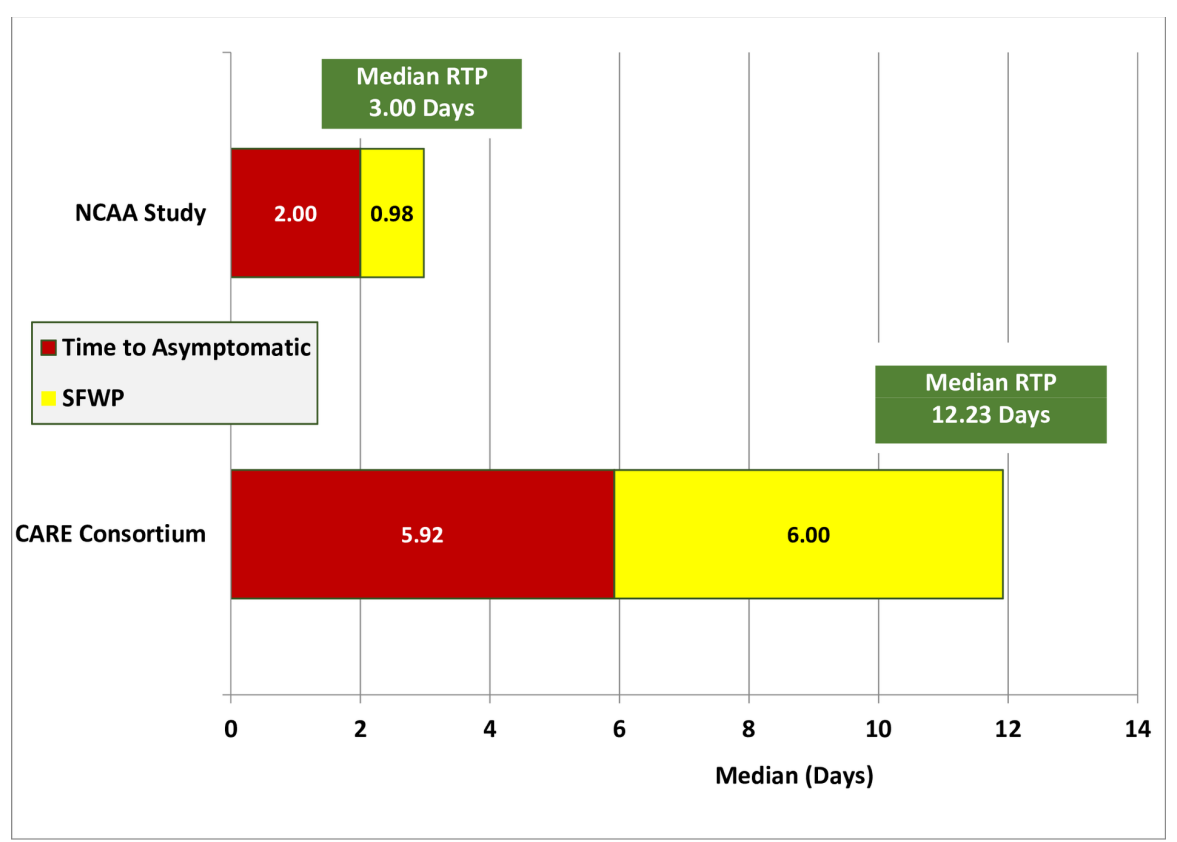

Figure 4 Median duration of symptom recovery, symptom-free waiting period (SFWP) and return to play (RTP) in National Collegiate Athletic Association (NCAA) Concussion Study and Concussion Assessment, Research and Education (CARE) Consortium cohorts. IQR: time to asymptomatic: NCAA (1.00-4.00 days), CARE (3.02-9.98 days). SFWP: NCAA (0.00-4.00 days), CARE (3.49-9.00 days). Total time for RTP: NCAA (1.00-8.00 days), CARE (8.04-18.92 days). Wilcoxon rank-sum tests of distributions in NCAA Study and CARE: time to asymptomatic $(p<0.0001)$. SFWP ( $<<0.0001)$. Total time for RTP $(p<0.0001)$. 
Table 2 Frequency and timing of same-season repeat concussion in NCAA Concussion Study and CARE Consortium cohorts

\begin{tabular}{|c|c|c|}
\hline & $\begin{array}{l}\text { NCAA Concussion Study } \\
(1999-2001)\end{array}$ & $\begin{array}{l}\text { CARE } \\
\text { Consortium } \\
(2014-2017)\end{array}$ \\
\hline Initial concussions (n) & 184 & 701 \\
\hline Same-season repeat concussion (n) & 12 & 27 \\
\hline $\begin{array}{l}\text { Rate of same-season repeat concussion } \\
\text { (\% of athletes with initial concussion) }\end{array}$ & 6.52 & 3.85 \\
\hline \multicolumn{3}{|l|}{$\begin{array}{l}\text { Interval between first and repeat } \\
\text { concussion (days) }\end{array}$} \\
\hline $\begin{array}{l}\text { Mean (SD) } \\
\text { Median }\end{array}$ & $\begin{array}{l}5.59(3.89) \\
4.0\end{array}$ & $\begin{array}{l}56.41 \\
(32.49) \\
49\end{array}$ \\
\hline \multicolumn{3}{|l|}{ Repeat concussions } \\
\hline$\leq 7$ days of initial injury, $\mathrm{n}(\%)$ & $9(75.0)$ & $1(3.7)$ \\
\hline$<10$ days of initial injury, $\mathrm{n}(\%)$ & $11(91.7)$ & $1(3.7)$ \\
\hline \multicolumn{3}{|c|}{$\begin{array}{l}\text { Interval between first and repeat concussion (mean difference }=50.82 \text { days; } 95 \% \mathrm{Cl} \\
38.37 \text { to } 63.27 ; p<0.0001, d=2.78 \text { ). } \\
\text { Rate of repeat concussion, } \chi^{2} \text { test } p=0.17 \text {. } \\
\text { Repeat concussion in } \leq 7 \text { days, Fisher's exact test } p<0.0001 \text {. } \\
\text { Repeat concussion in }<10 \text { days, Fisher's exact test } p<0.0001 \text {. } \\
\text { CARE, Concussion Assessment, Research and Education; NCAA, National Collegiate } \\
\text { Athletic Association. }\end{array}$} \\
\hline
\end{tabular}

\section{Within-season repeat concussion}

The rate of within-season repeat concussion in CARE $3.85 \%$; $\mathrm{n}=27$ of 701$)$ was $41 \%$ lower than in the NCAA Study $(6.52 \%$; $\mathrm{n}=12$ of 184$)\left(\chi^{2}\right.$ test, $\left.\mathrm{p}=0.17\right)$. Further, the average interval between first and repeat concussion in CARE was 50.82 days longer than in the NCAA Study (95\% CI 38.37 to 63.27; $\mathrm{p}<0.0001 ; d=2.78)$. In CARE, there was only one repeat concussion inside 10 days of initial injury (3.7\% of all withinseason repeats), when $91.7 \%(n=11$ of 12$)$ of repeat concussions occurred in the NCAA Study (Fisher's exact test, $\mathrm{p}<0.0001$ ). Occurrence of repeat concussion was not associated with the occurrence of LOC, PTA or the date of initial injury during the season (table 2).

\section{DISCUSSION}

Our analysis from the NCAA Concussion Study (1999-2001) and current CARE Consortium (2014-2017) indicates a major shift in approaches to clinical management of SRC in NCAA collegiate football players over the past 15 years. The findings from CARE highlight a combination of lengthier recovery time in current-day athletes and universal employment of an SFWP by sports medicine professionals, in accordance with recent international consensus recommendations. ${ }^{12}{ }^{14}$ CARE athletes were withheld from play nearly 10 days longer than the NCAA Study cohort. Most importantly, our findings suggest that this extended recovery period and avoidance of head impact exposure experienced by current-day collegiate football players is associated with a reduction in repeat concussions during the acute postinjury period ( $\leq 10$ days after injury) when the brain appears to be particularly vulnerable to the effects of repetitive trauma. Reduction in risk of repeat concussion during this window of vulnerability also reduces the theoretical risk of catastrophic injury associated with SRC. We cannot exclude the possibility that other system or cultural changes over this same period (eg, increased presence of medical staff, NCAA policy on RTP, improved education, athlete awareness of risks, rule changes, improved equipment) may also have impacted the observed risk of repeat concussion.
RTP, then and now

The distribution of recovery time across athletes in the NCAA Study and CARE differed dramatically. CARE athletes reported postconcussive symptoms lasting several days longer than players in the earlier NCAA Study, despite a pattern suggestive of more severe acute injury characteristics in the NCAA Study. Nearly one-third of players in the NCAA Study reported complete symptom recovery within a day of injury and 9 out of 10 players reportedly recovered within a week. ${ }^{67}$ In contrast, only $5 \%$ of concussed players in CARE recovered within the first day, and nearly half of CARE athletes reported symptoms for more than 1 week after injury. Although our study does not allow us to directly determine the impact of specific educational initiatives targeted at college athletes during the 15 -year interval between the NCAA Study and CARE, ${ }^{20}$ these findings further suggest that current-day athletes may be more aware of concussion symptoms and more likely to report their injury. ${ }^{26-28}$

Our main findings also highlight a major change in approaches to clinical management of SRC by sports medicine professionals. Our findings on current-day employment of an SFWP and time for RTP, particularly in an observational study without any major intervention under investigation, suggest a major culture change around SRC over the past 20 years. During the era that predated widely accepted international consensus guidelines for SRC, it was common for athletes to resume participation within the same practice or game. ${ }^{29}$ Our results suggest that implementation of an SFWP with a structured RTP protocol is now essentially universal, and that same-day RTP after concussion is rare. Over $97 \%$ of CARE athletes had an SFWP of a day or more, including $40 \%$ for more than 1 week. These results are in stark contrast to the NCAA Study, where over $40 \%$ of players had no SFWP at all. It is notable that the injuries in the NCAA Study appeared to be more severe, but were less conservatively managed than in CARE.

The combination of lengthier recovery time reported by athletes and more systematic implementation of SFWP had the combined result of a very different RTP trajectory in CARE athletes, compared with the NCAA Study. Not a single CARE player returned to play within a day of injury, compared with nearly one-third of concussed players in the NCAA Study. Further, over $80 \%$ of CARE Consortium athletes were withheld from play for more than 1 week, whereas $75 \%$ of NCAA Study athletes actually returned to play inside a week of injury. RTP in our study was not associated with number or prior concussions, indicating a broader change in injury management (not restricted to athletes with history of multiple concussions).

\section{Impact on reducing risk of repetitive concussion}

Our findings provide additional evidence that contemporary approaches to clinical management of concussion, in accordance with international consensus recommendations, have meaningful health and safety benefits to athletes. Original findings from the NCAA Study suggested that football players were at heightened risk of repeat concussion within the first 10 days after initial concussion. Animal studies have also demonstrated that exposure to additional head impacts or concussive injury during the acute period after initial injury can result in more severe disruption of normal brain function and lengthier recovery time. ${ }^{30} 31$ A pilot study demonstrated the same effect among athletes who sustained a second concussion within 15 days of initial injury. ${ }^{10}$ Further, emerging data suggest that the time course of physiological recovery extends beyond the point of observed clinical recovery after SRC. ${ }^{32-34}$ Based on the existing evidence, 
international consensus guidelines now recommend that once symptoms stabilise or resolve, an athlete completes a programme of graded exertion during the SFWP, prior to returning to full RTP after concussion. ${ }^{14}$

The overall occurrence of within-season repeat concussion in CARE was $41 \%$ lower than that of the NCAA Study and the rate in CARE was more than four times lower than earlier published reports from the 1990s. ${ }^{4}$ More importantly, in four seasons of CARE, there was only one case of repeat concussion within the first 10 days of initial injury, when over $90 \%$ of repeat concussions occurred in the NCAA Study during this same window. This observation supports the contention that a combination of lengthier clinical recovery time and SFWP before full RTP has a significant impact on protecting athletes by allowing adequate time for neurobiological recovery and reducing the risk of repeat concussion during this vulnerable period.

\section{Study limitations}

Several limitations of the current analysis warrant recognition. To the extent possible, limitations are mitigated by the consistencies between the cohorts, methods and variables compared between the NCAA Study and CARE. Although major efforts towards achieving best practices in concussion management (eg, RTP protocols) were implemented during the interim between these two studies, our analysis did not allow us to isolate the effect of specific clinical management strategies from other contributing factors over that same period. It may also be likely that clinicians became more sensitive to detecting concussion in college athletes, resulting in higher rates of reported and diagnosed concussion in CARE and other contemporary studies. ${ }^{28}$ Our samples consisted of NCAA football players only, which limits the generalisability of these findings to male and female athletes in other sports and competitive levels. Further, college athletes in our studies are cared for daily by highly trained medical professionals, which impacts our ability to generalise our findings to clinical management of concussion in other settings. While both studies involved trained physicians and athletic trainers engaged in diagnosis of management of concussion, we are unable to determine the breakdown of cases managed by physicians versus athletic trainers. We recognise that our main measure of recovery was based on self-report of symptom resolution by the athlete, and that concussion assessment methods (eg, neurocognitive testing) have evolved over the time between these studies. While modern tools assist in clinical assessment, the medical professional's clinical judgement employed in this study remains the gold standard for injury management and RTP. Further, published studies have consistently demonstrated that symptom measures account for the largest and longest lasting effect sizes after SRC. ${ }^{35}$ Therefore, the recovery times reported in both the NCAA Study and CARE are likely the most conservative (ie, longest). Also, neither the NCAA Study nor CARE is randomised, controlled clinical trial (RCT) that would allow us to systematically manipulate clinical management (eg, SFWP, RTP time) or directly assess the efficacy of specific clinical management strategies. Although a true RCT that involves rapid RTP would not likely be permissible by human research protections, further study on approaches to rehabilitation and prevention of concussion is strongly recommended, based on our main findings.

\section{CONCLUSION}

In conclusion, our findings suggest that modern American college football athletes are reporting a longer recovery time after SRC and clinicians are more conservative in concussion management than 15 years earlier. Our findings support contemporary international consensus recommendations that athletes observe a lengthier period of recovery and rehabilitation prior to RTP after SRC. This approach allows adequate time for brain recovery after injury, and reduces an athlete's risk of repetitive concussion during the acute window of cerebral vulnerability, which may be crucial to preventing persistent or chronic neurological health problems in athletes.

\section{Author affiliations}

${ }^{1}$ Neurosurgery, Medical College of Wisconsin, Milwaukee, Wisconsin, USA

${ }^{2}$ Kinesiology, University of Michigan, Ann Arbor, Michigan, USA

${ }^{3}$ Psychiatry, Indiana University School of Medicine, Indianapolis, Indiana, USA

${ }^{4}$ Department of Biostatistics, Indiana University School of Medicine, Indianapolis, Indiana, USA

${ }^{5}$ Takeda Pharmaceutical, Osaka, Japan

${ }^{6}$ Department of Epidemiology and Biostatistics, School of Public Health-Bloomington, Indiana University System, Bloomington, Indiana, USA

${ }^{7}$ Neurosurgery and Neurology, Medical College of Wisconsin, Milwaukee, Wisconsin, USA

${ }^{8}$ Department of Neurosurgery, Medical College of Wisconsin, Milwaukee, Wisconsin, USA

${ }^{9}$ Department of Cell Biology, Medical College of Wisconsin, Milwaukee, Wisconsin, USA

${ }^{10}$ Injury Prevention Research Center, University of North Carolina at Chapel Hill, Chapel Hill, North Carolina, USA

${ }^{11}$ Sports Medicine Research Laboratory, University of North Carolina at Chapel Hill, Chapel Hill, North Carolina, USA

Correction notice This article has been corrected since it published Online First. The author group 'CARE Consortium Investigators' has been added.

Contributors The authors thank Jody Harland, Janetta Matesan, Larry Riggen (Indiana University); Ashley Rettmann (University of Michigan); Melissa Koschnitzke (Medical College of Wisconsin); Michael Jarrett, Vibeke Brinck and Bianca Byrne (Quesgen); Melissa Niceley Baker and Sara Dalton (Datalys Center for Sports Injury Research and Prevention); and the research and medical staff at each of the CARE participation sites. Contributing CARE Consortium Investigators are listed alphabetically by institution: April Marie (Reed) Hoy, MS, ATC (Azusa Pacific University); Joseph B Hazzard Jr, EdD, ATC (Bloomsburg University); Louise A Kelly, PhD (California Lutheran University); Justus D Ortega, PhD (Humboldt State University); Nicholas Port, PhD (Indiana University); Margot Putukian, MD (Princeton University); T Dianne Langford, PhD, and Ryan Tierney, PhD, ATC (Temple University); Paul Pasquina, MD (Uniformed Services University of Health Sciences); Darren E Campbell, MD, Jonathan Jackson, MD, and Gerald McGinty, DPT (US Air Force Academy); Patrick O'Donnell, MHA (US Coast Guard Academy); Kenneth Cameron, MPH, PhD, ATC, Megan Houston, PhD, and Steven Svoboda, MD (US Military Academy); Christopher Giza, MD, Joshua Goldman, MD, and Jon DiFiori, MD (University of California-Los Angeles); Holly J Benjamin MD (University of Chicago); Thomas Buckley, EdD, ATC, and Thomas W Kaminski, PhD, ATC (University of Delaware); James R Clugston, MD, MS (University of Florida); Julianne D Schmidt, PhD, ATC (University of Georgia); Luis A Feigenbaum, PT, DPT, ATC, LAT (University of Miami); James T Eckner, MD, MS (University of Michigan); Jason P Mihalik, PhD, CAT(C), ATC (University of North Carolina at Chapel Hill); Jessica Dysart Miles, PhD, ATC (University of North Georgia); Scott Anderson, ATC (University of Oklahoma); Kristy Arbogast, PhD, and Christina L Master, MD (University of Pennsylvania); Micky Collins, PhD, and Anthony P Kontos, PhD (University of Pittsburgh Medical Center); Jeffrey J Bazarian, MD, MPH (University of Rochester); Sara PD Chrisman, MD, MPH (University of Washington); M Alison Brooks, MD, MPH (University of Wisconsin); Stefan Duma, PhD, and Steven Rowson, PhD (Virginia Tech); Christopher M Miles, MD (Wake Forest University); Brian H Dykhuizen, MS, ATC (Wilmington College); Laura Lintner, DO (Winston-Salem State University).

Funding This publication was made possible, in part, with support from the Grand Alliance Concussion Assessment, Research and Education (CARE) Consortium, funded, in part by the National Collegiate Athletic Association (NCAA) and the Department of Defense (DOD). The US Army Medical Research Acquisition Activity, 820 Chandler Street, Fort Detrick, MD 21702-5014 is the awarding and administering acquisition office. This work was supported by the Office of the Assistant Secretary of Defense for Health Affairs through the Psychological Health and Traumatic Brain Injury Program under Award No W81XWH-14-2-0151.

Disclaimer Opinions, interpretations, conclusions and recommendations are those of the author and are not necessarily endorsed by the Department of Defense (DHP funds).

Competing interests None declared. 
Patient consent for publication Not required.

Ethics approval The NCAA Concussion Study was approved by the institutional review boards for protection of human research subjects at the University of North Carolina (KMG) and Waukesha Memorial Hospital (MMC). For the CARE Consortium, the University of Michigan Institutional Review Board, the US Army Medical Research and Materiel Command Human Research Protection Office, and the local institutional review board at each of the study sites reviewed all study procedures. The study was performed in accordance with the standards of ethics outlined in the Declaration of Helsinki. All participants in both studies granted written informed consent prior to participation in the study.

Provenance and peer review Not commissioned; externally peer reviewed.

Data availability statement Data for this study from the NCAA Concussion Study are available upon reasonable request from the corresponding author. Data for this study from the CARE Consortium are publicly available from the National Institute of Health (NIH) Federal Interagency Traumatic Brain Injury (TBI) Research (FITBIR) Informatics System (https://fitbir.nih.gov).

\section{ORCID iD}

Michael McCrea http://orcid.org/0000-0001-9791-9475

\section{REFERENCES}

1. Ferrara MS, McCrea M, Peterson $\mathrm{CL}$, et al. A survey of practice patterns in concussion assessment and management. J Athl Train 2001;36:145-9.

2. Notebaert AJ, Guskiewicz KM. Current trends in athletic training practice for concussion assessment and management. J Athl Train 2005;40:320-5.

3. Pellman EJ, Powell JW, Viano DC, et al. Concussion in professional football: epidemiological features of game injuries and review of the Literature-Part 3. Neurosurgery 2004;54:81-96. discussion 94-86.

4. Guskiewicz KM, Weaver NL, Padua DA, et al. Epidemiology of concussion in collegiate and high school football players. Am J Sports Med 2000;28:643-50.

5. McCrea M, Hammeke T, Olsen G, et al. Unreported concussion in high school football players: implications for prevention. Clin I Sport Med 2004;14:13-17.

6. Guskiewicz KM, McCrea M, Marshall SW, et al. Cumulative effects associated with recurrent concussion in collegiate football players. JAMA 2003;290:2549-55.

7. McCrea M, Guskiewicz KM, Marshall SW, et al. Acute effects and recovery time following concussion in collegiate football players. JAMA 2003;290:2556-63.

8. Giza CC, Hovda DA. The neurometabolic cascade of concussion. J Athl Train 2001;36:228-35.

9. Giza CC, Hovda DA. The new neurometabolic cascade of concussion. Neurosurgery 2014;75(5):S24-S33.

10. Vagnozzi R, Signoretti S, Tavazzi B, et al. Temporal window of metabolic brain vulnerability to concussion: a pilot $1 \mathrm{H}$-magnetic resonance spectroscopic study in concussed athletes-part III. Neurosurgery 2008;62:1286-95. discussion 1295-1286.

11. McCrory P, Meeuwisse W, Johnston $\mathrm{K}$, et al. Consensus statement on concussion in sport: the 3rd international Conference on concussion in sport held in Zurich, November 2008. Br J Sports Med 2009;43(Suppl_1):i76-84.

12. McCrory P, Meeuwisse WH, Aubry M, et al. Consensus statement on concussion in sport: the 4th International Conference on concussion in sport held in Zurich, November 2012. Br J Sports Med 2013:47:250-8.

13. McCrory Pet al. Summary and agreement statement of the 2nd International Conference on concussion in sport, Praque 2004. Br J Sports Med 2005;39(Supplement 1):i78-86.

14. McCrory P, Meeuwisse W, Dvorak J, et al. Consensus statement on concussion in sport-the 5th International Conference on concussion in sport held in Berlin, October 2016. Br. J. Sports Med 2017;26
15. Giza CC, Kutcher JS, Ashwal S, et al. Summary of evidence-based guideline update: evaluation and management of concussion in sports: report of the Guideline Development Subcommittee of the American Academy of Neurology. Neurology 2013;80:2250-7.

16. Harmon KG, Drezner JA, Gammons M, et al. American medical Society for sports medicine position statement: concussion in sport. Br J Sports Med 2013;47:15-26.

17. Broglio SP, Cantu RC, Gioia GA, et al. National athletic trainers' Association position statement: management of Sport concussion. J Athl Train 2014;49:245-65.

18. Sarmiento K, Hoffman R, Dmitrovsky Z, et al. A 10-year review of the Centers for disease control and prevention's heads up initiatives: bringing concussion awareness to the forefront. I Safety Res 2014;50:143-7.

19. NCAA Sports Science Institute. Concussion safety protocol management. Available: http://www.ncaa.org/sport-science-institute/concussion-safety-protocol-management [Accessed 21 Sep 2017].

20. NCAA Sports Science Institute. Concussion educational resources. Available: http:// www.ncaa.org/sport-science-institute/concussion-educational-resources [Accessed 22 Sep 2017].

21. Broglio SP, McCrea M, McAllister T, et al. A national study on the effects of concussion in collegiate athletes and US military service Academy members: the NCAA-DoD concussion assessment, research and education (care) Consortium structure and methods. Sports Med 2017.

22. Kelly JP, Rosenberg JH. Diagnosis and management of concussion in sports. Neurology 1997;48:575-80

23. Practice parameter: the management of concussion in sports (summary statement). Report of the Quality Standards Subcommittee. Neurology 1997;48:581-5.

24. Carney N, Ghajar J, Jagoda A, et al. Concussion guidelines step 1: systematic review of prevalent indicators. Neurosurgery 2014;75(Suppl 1):S3-15.

25. Buuren Svan, Groothuis-Oudshoorn K. Mice: Multivariate Imputation by Chained Equations in R. Journal of Statistical Software 2011;45.

26. Pfaller AY, Nelson LD, Apps JN, et al. Frequency and outcomes of a symptom-free waiting period after sport-related concussion. Am J Sports Med 2016;44:2941-6.

27. LaRoche AA, Nelson LD, Connelly PK, et al. Sport-related concussion reporting and state legislative effects. Clin I Sport Med 2016;26:33-9.

28. Yang J, Comstock RD, Yi H, et al. New and recurrent concussions in high-school athletes before and after traumatic brain injury laws, 2005-2016. Am J Public Health 2017:e1-7.

29. McCrea M, Guskiewicz K, Randolph C, et al. Effects of a symptom-free waiting period on clinical outcome and risk of reinjury after sport-related concussion. Neurosurgery 2009;65:876-83. discussion 882-873.

30. Prins ML, Hales A, Reger M, et al. Repeat traumatic brain injury in the juvenile rat is associated with increased axonal injury and cognitive impairments. Dev Neurosci 2010;32:510-8.

31. Prins ML, Alexander D, Giza CC, et al. Repeated mild traumatic brain injury: mechanisms of cerebral vulnerability. J Neurotrauma 2013;30:30-8.

32. Wang Y, Nelson LD, LaRoche AA, et al. Cerebral blood flow alterations in acute sportrelated concussion. J Neurotrauma 2016;33:1227-36.

33. Lancaster MA, Olson DV, McCrea MA, et al. Acute white matter changes following sport-related concussion: a serial diffusion tensor and diffusion kurtosis tensor imaging study. Hum Brain Mapp 2016;37:3821-34.

34. Kamins J, Bigler E, Covassin T, et al. What is the physiological time to recovery after concussion? A systematic review. Br J Sports Med 2017;51:935-40.

35. Nelson LD, LaRoche AA, Pfaller AY, et al. Prospective, head-to-head study of three computerized neurocognitive assessment tools (CNTs): reliability and validity for the assessment of sport-related concussion. J Int Neuropsychol Soc 2016;22:24-37. 